\title{
A cross sectional analysis of behaviors related to operating gas stoves and pneumonia in U.S. children under the age of 5
}

\author{
Eric S Coker ${ }^{*}$, Ellen Smit, Anna K Harding, John Molitor and Molly L Kile
}

\begin{abstract}
Background: Poorly ventilated combustion stoves and pollutants emitted from combustion stoves increase the risk of acute lower respiratory illnesses (ALRI) in children living in developing countries but few studies have examined these issues in developed countries. Our objective is to investigate behaviors related to gas stove use, namely using them for heat and without ventilation, on the odds of pneumonia and cough in U.S. children.
\end{abstract}

Methods: The National Health and Nutrition Examination Survey (1988-1994) was used to identify children < 5 years who lived in homes with a gas stove and whose parents provided information on their behaviors when operating their gas stoves and data on pneumonia $(N=3,289)$ and cough $(N=3,127)$. Multivariate logistic regression models were used to examine the association between each respiratory outcome and using a gas stove for heat or without ventilation, as well as, the joint effect of both behaviors.

Results: The adjusted odds of parental-reported pneumonia (adjusted odds ratio $[a \mathrm{OR}]=2.08,95 \%$ confidence interval $[\mathrm{Cl}]: 1.08,4.03)$ and cough $(\mathrm{aOR}=1.66,95 \% \mathrm{Cl}: 1.14,2.43)$ were higher among children who lived in homes where gas stoves were used for heat compared to those who lived in homes where gas stoves were only used for cooking. The odds of pneumonia ( $\mathrm{aOR}=1.76,95 \% \mathrm{Cl}: 1.04,2.98)$, but not cough $(\mathrm{aOR}=1.23,95 \% \mathrm{Cl}: 0.87,1.75$ ), was higher among those children whose parents did not report using ventilation when operating gas stoves compared to those who did use ventilation. When considering the joint association of both stove operating conditions, only children whose parents reported using gas stoves for heat without ventilation had significantly higher odds of pneumonia (aOR $=3.06,95 \% \mathrm{Cl}$ : $1.32,7.09)$ and coughing ( $\mathrm{aOR}=2.07,95 \% \mathrm{Cl}: 1.29,3.30)$ after adjusting for other risk factors.

Conclusions: Using gas stoves for heat without ventilation was associated with higher odds of pneumonia and cough among U.S. children less than five years old who live in homes with a gas stove. More research is needed to determine if emissions from gas stoves ventilation infrastructure, or modifiable behaviors contribute to respiratory infections in children.

Keywords: Gas stove, Heating, Ventilation, Pneumonia, Respiratory infection, NHANES

\section{Background}

In the United States, acute lower respiratory infections (ALRI), which include bronchitis, influenza and pneumonia, area leading cause of hospitalizations among children under five years of age. In 2010, it was estimated that there were 313,322 hospitalizations for new cases of ALRI in the United States among children in this age group [1]. The introduction of pneumococcal

\footnotetext{
* Correspondence: cokerer@onid.oregonstate.edu

College of Public Health and Human Sciences, Oregon State University, Milam Hall, Corvallis, OR 97331, USA
}

C) Biomed Central

(c) 2015 Coker et al.; licensee BioMed Central. This is an Open Access article distributed under the terms of the Creative Commons Attribution License (http://creativecommons.org/licenses/by/4.0), which permits unrestricted use, distribution, and reproduction in any medium, provided the original work is properly credited. The Creative Commons Public Domain Dedication waiver (http://creativecommons.org/publicdomain/zero/1.0/) applies to the data made available in this article unless otherwise stated. and Haemophilus influenza type b vaccines over the past decade significantly decreased overall pneumonia incidence $[2,3]$, yet the rates for non-vaccine serotypes of pneumonia have largely remained unchanged among children under five years of age [2,4]. Early childhood ALRIs may also have persistent effects on respiratory health and have been linked with an increased risk of asthma later in childhood [5-7]. Consequently, it remains important to identify environmental factors that contribute to, or that can prevent, ALRI in young children. 
Researchers have identified many risk factors for ALRI in young children including low birth weight, lack of breastfeeding, crowded housing conditions, exposure to tobacco smoke, low household income, low maternal educational attainment, day care attendance, and incomplete immunizations [1,8]. Indoor air pollution from combustion stoves and heaters are also known risk factors for ALRI in young children $[1,8,9]$. The vast majority of the data supporting the association between ALRI and indoor air pollution has been collected in developing countries and has been attributed to burning solid fuels (e.g. wood, coal, and charcoal) [9-11] indoors for cooking and heating. However, the health impact from indoor air pollution generated from gas stoves on respiratory infections in children living in developed countries is less understood [12].

Data from indoor air pollution studies conducted in developed countries indicate that using gas stoves leads to elevated concentrations of nitrogen dioxide and particulate matter inside homes [12-17]. Studies have also reported a significant relationship between using a gas stove in the home and increased prevalence of chronic lower respiratory illness (e.g. asthma) [18-21]. Some data show that self-reported behaviors and housing conditions related to gas stove use are associated with reduced lung function and chronic lower respiratory illness and lower respiratory symptoms in children. For example, previous analyses of NHANESIII found increased prevalence of asthma, chronic bronchitis, and wheeze among children whose parents reported using a gas stove for heat $[22,23]$ or using a gas stove without ventilation [22]. Higher prevalence of childhood ALRI have also been noted in homes with gas stoves compared to homes with electric stoves, however, this finding has not been consistently reported [24-32]. These conflicting results between studies could be related to not taking into account gas stove-related behaviors, such as using it as an auxiliary heat source in the home, or housing conditions known to influence indoor air pollution exposures such as the lack of an exhaust vent near the stove [33-41].

Numerous studies have demonstrated that using a gas stove without ventilation contributes to elevated indoor air pollution concentrations [42-46]. For example, a recent report indicated $62 \%, 9 \%$ and $53 \%$ of Southern Californian homes that used gas stoves without ventilation exceeded acute health based standards for $\mathrm{NO}_{2}$, $\mathrm{CO}$, and formaldehyde, respectively [47]. In addition, research data has found that using a gas stove as a supplemental heating source, as is done in some homes in the U.S. [48], can lead to elevated concentrations of $\mathrm{NO}_{2}$ [46]. Therefore, we hypothesized that children under five years of age who lived in households that used a gas stove without ventilation or where the gas stove was used as a heating source would have an elevated prevalence of pneumonia compared to children who lived in households that used a gas stove with ventilation and only for cooking. We further hypothesized that the prevalence of cough- a non-specific yet important pneumoniarelated symptom- would also be higher among children who lived in homes that used a gas stove without ventilation or as a heat source.

\section{Methods}

\section{Study population}

The National Center for Health Statistics conducted the Third National Health and Nutrition Examination Survey (NHANES III) from 1988-1994. This is a nationally representative cross-sectional survey of the civilian non-institutionalized U.S. population. Participants were administered standardized interviews in their homes and underwent physical examinations and laboratory testing in mobile examination centers.

The purpose of this analysis was to examine the association between respiratory infections in children under 5 years and behaviors related to the use of a gas stove. Subsequently, this analysis was restricted to children $<5$ years of age whose parents: (1) responded to questions about pneumonia and cough, (2) reported that a gas stove was used in the past twelve months in their child's primary residence, (3) provided information on their use of ventilation when operating the stove, and (4) provided information when asked if they used the gas stove for heat. There were 3,314 children under the age of 5 who lived in homes that reported using a gas stove for cooking. Of those, 3,295 and 3,132 parents provided information on their child's pneumonia history and cough, respectively. Finally, complete covariate information was available on 3,308 and 3,146 for pneumonia and cough, respectfully.

\section{Ethics statement}

Human subjects approval and documentation of consent for NHANES III child participants was obtained through the National Center for Health Statistics Internal Review Board. Parents or legal guardians of participants under the age of 7 years provided informed consent [49].

\section{Self-reported respiratory outcomes}

Respondents were asked whether their child had pneumonia in the past 12 months (yes/no). This pneumonia variable has been used in two previously published studies that analyzed NHANESIII [50,51]. We also included coughing as a non-specific secondary respiratory outcome that could also be related to respiratory infections. Respondents were also asked if the child had "problems with coughing" in the past 12 months (yes/no) [52]. 


\section{Behaviors related to operating gas stoves}

Children were assigned into different exposure groups based on how their parent responded to a series of questions related to stove use. Respondents were asked "Is a gas stove or oven used for cooking (yes/no)?" If they reported using a gas stove for cooking, they were then asked: "During the past 12 months was the stove or oven ever used to heat this place (yes/no)?" Respondents that answered yes were assigned to the 'gas stove heating' group and those who answered no were assigned to the 'no gas heating' reference group. Additionally, respondents who reported cooking with a gas stove were also asked "Is there an exhaust fan near this stove that sends fumes outside the home (yes/no)?" Respondents that answered yes were asked about frequency of exhaust fan usage (never, rarely, sometimes, or always) [52]. Those who reported either not having an exhaust fan or never using the exhaust fan were assigned to the 'unvented gas stove' group. Those who answered that they used their exhaust fan rarely, sometimes, or always were assigned to the 'vented gas stove' reference group. To evaluate the joint association of venting and heating, we combined these two categories to create mutually exclusive groups that were: (1) heating with an unvented gas stove, (2) heating with a vented gas stove, (3) no heating with an unvented gas stove, and (4) no heating with a vented gas stove (reference group).

\section{Covariates}

Selected characteristics were assessed for their relationship to respiratory outcomes and parental behaviors regarding gas stoves. Covariates were selected by a reviewing the literature [53]. These included: child age and sex, parental race-ethnicity, breast-feeding (never/ ever), day care attendance (yes/no), household crowding $(<0.5$ persons/room, $0.5-1$ persons/room, and $>1$ persons/room) [54], maternal smoking during pregnancy (yes/no), environmental tobacco smoking in the home (yes/no), type of heating furnace in the home (none, gas, electrical, oil, propane, other), low birth weight (yes/no), U.S. census region, type of residence (urban versus rural), household income $<\$ 20,000$, and household referent education level. NHANES interviews and examinations are conducted in the southern states in winter months and northern states in the summer months for operational reasons. We therefore included U.S. census region (Northeast, Midwest, South, West) to not only control for differences in interview time periods, but also to control for known differences in gas stove-related behaviors and pneumonia incidence that are related to geographic regions in the U.S.. We opted to control for socioeconomic status using household income $<\$ 20,000$ as our income indicator given its low non-response rate $(<3 \%)$ whereas poverty income ratio had a much higher non-response rate (11\%) and respondents differed significantly by race, geographic region, age of the child, and environmental tobacco smoke (all of which are potential confounders themselves) compared to those with these data.

\section{Statistical analysis}

All analyses were conducted using the appropriate sample weights to correct for differential selection probabilities and to adjust for non-coverage and nonresponse in Stata version 12.1 (StataCorp, College Station, TX). The weighted prevalence (\%) and 95\% confidence intervals $(95 \% \mathrm{CI})$ of pneumonia and cough were calculated for the different gas stove usage groups. Chi-square tests assessed the association between health outcomes and the selected covariates, as well as, the relationship between behaviors related to operating gas stoves and select socio-demographic characteristics. Covariates were included in the following multivariate logistic regression models if they were associated with pneumonia or cough at $\alpha<0.10$ or if previous literature indicated that they were risk factors for pneumonia (e.g. parental educational levels and household income) to control for potential confounding. Subsequently, the models for pneumonia were adjusted for age, race-ethnicity, indoor tobacco smoke, breastfeeding, US Census region, household income under $\$ 20,000$, and parental education level, whereas the models for cough were adjusted for race-ethnicity, indoor tobacco smoke, breastfeeding, US Census region, household income under $\$ 20,000$, and parental education level. Separate multiple logistic regression models were used to estimate the odds ratio and 95\% CI for each respiratory outcome. Model 1 compared the respiratory outcomes in children from homes that reported using a gas stove for heating to children from homes that did not use a gas stove for heat. Model 2 compared the respiratory outcomes in children from homes where a gas stove was used without ventilation to children from homes where a gas stove was used with ventilation. Model 3 compared the respiratory outcomes in children from homes where: $i$ ) gas stove was used for heat without ventilation, $i i$ ) gas stove was used for heat with ventilation, iii) gas stove not used for heat without ventilation, and $i v$ ) gas stove not used for heat and with ventilation (reference group). In addition, we used a chi-squared to test the association between self-reported ventilation and heating with a gas stove.

\section{Results}

For all homes with a gas stove, the weighted prevalence of pneumonia and cough among children under-five years old in NHANES III was 3.23\% (95\% CI: 2.52, 3.98) 
and 33.06\% (95\% CI: 30.81, 35.31), respectively. Among all gas stove users, $12.9 \%$ (95\% CI: 10.5, 15.3) of the respondents reported using their gas stove for heating purposes and $46.6 \%$ (95\% CI: $42.2,51.0$ ) of the participants reported operating their gas stoves without ventilation. Furthermore, participants who did not use ventilation when operating their gas stoves were 2.3 times more likely ( $p=0.0004$ ) to report using their gas stove for heating purposes compared to those participants who reported using ventilation when operating their gas stove; thus indicating there was significant overlap between those who used a gas stove for heating and those who did not use ventilation while operating a gas stove.

The crude weighted prevalence of each respiratory outcome by heating and ventilation status in children living in homes with a gas stove is described in Table 1. The crude prevalence of parental-reported pneumonia was higher among children where the respondents did not report using ventilation compared to those who reported using ventilation $(4.17 \%$ [95\% CI: $2.71,5.63]$ versus $2.41 \%$ [95\% CI: 1.64, 3.18], $\mathrm{p}<0.05$ ). The crude prevalence of parental-reported pneumonia was also higher among children where the participant reported using their gas stove for heat compared to those who only used their gas stove for cooking (5.65\% [95\% CI: 2.56, 9.66] versus 2.71\% [95\% CI: 2.10, 3.49], p < 0.01). Further, the crude prevalence of parental-reported pneumonia was highest among children where the respondents reported using their gas stove without ventilation and for heat compared to those who only used their gas stove for cooking with ventilation $(6.83 \%$ [95\% CI: 3.74, 12.14]) versus $2.31 \%$ [95\% CI: 1.67, 3.19], $\mathrm{p}<0.01)$. Additionally, child's age, household referent education level, and U.S. Census region were also significantly associated with parentalreported pneumonia (data not shown). Other covariates, such as income, race-ethnicity, breastfeeding, and environmental tobacco smoke were forced into the model due to their importance in the literature as they relate to childhood ALRIs. Covariates that were significantly associated with cough included environmental tobacco smoke, raceethnicity, ever breastfed, and region (data not shown). Subsequently, these covariates were included in the following multivariate models. Using a gas heating furnace was not included in the final models since this variable was not related to either respiratory outcome in our study and there was no evidence for confounding attributable to homes using a gas furnace.

The association between using a gas stove for heat and each respiratory outcome adjusted for confounders is described in Table 2. After adjusting for other risk factors, the adjusted odds of pneumonia in the past 12 months was twice as high (aOR: 2.08, 95\% CI: 1.08, 4.03) among children under 5 years of age who lived in a household where gas stoves were used for heat compared to those who resided in homes where gas stoves were only used for cooking. Similarly, the odds that children had a problem with coughing in the past 12 months was significantly higher (aOR: 1.66, 95\% CI: 1.14, 2.43) among children who lived in a household where the participant reported using their gas stove for heat compared to children residing in homes where gas stoves were only used for cooking after adjusting for other risk factors.

The association between using a gas stove without ventilation on each respiratory outcome after adjusting for confounders is presented in Table 3. After adjusting for other risk factors, the odds that children under

Table 1 Prevalence of ALRI among children $<5$ years stratified by gas stove ventilation and heating status

\begin{tabular}{|c|c|c|c|c|c|c|}
\hline & \multicolumn{3}{|c|}{ Pneumonia } & \multicolumn{3}{|c|}{ Coughing } \\
\hline & $\mathbf{N}$ & $\%$ & $95 \% \mathrm{Cl}$ & $\mathbf{N}$ & $\%$ & $95 \% \mathrm{Cl}$ \\
\hline All & 120 & 3.24 & $2.52,3.98$ & 1,144 & 33.06 & $30.81,35.31$ \\
\hline \multicolumn{7}{|c|}{ Was ventilation used when operating gas stove } \\
\hline Yes & 48 & 2.41 & $1.64,3.18$ & 567 & 32.51 & $28.33,36.69$ \\
\hline No & 72 & $4.17^{*}$ & $2.71,5.63$ & 574 & 33.40 & $28.99,37.80$ \\
\hline \multicolumn{7}{|c|}{ Was gas stove used for heating } \\
\hline Yes & 86 & $5.65^{* *}$ & $2.56,9.66$ & 231 & 40.34 & $31.86,49.43$ \\
\hline No & 32 & 2.71 & $2.10,3.49$ & 908 & 31.80 & $29.16,34.57$ \\
\hline \multicolumn{7}{|c|}{ Heating and ventilation status combined } \\
\hline Unvented and Heat & 25 & $6.83^{* *}$ & $3.74,12.14$ & 157 & 44.02 & $34.22,54.31$ \\
\hline Vented and Heat & 7 & $3.54^{\mathrm{a}}$ & $1.56,7.80$ & 74 & 33.73 & $22.02,47.84$ \\
\hline Unvented and only cooking & 45 & 3.23 & $2.12,4.89$ & 412 & 30.87 & $27.01,35.03$ \\
\hline Vented and only cooking & 41 & 2.31 & $1.67,3.19$ & 493 & 32.46 & $28.32,36.88$ \\
\hline
\end{tabular}

Abbreviations: $\mathrm{Cl}$, confidence interval.

${ }^{*} P<0.05$.

**P $<0.01$.

${ }^{a}$ May be statistically unreliable, relative standard error (SE/percent) $>30 \%$. 
Table 2 Odds ratios for ALRI among children $<5$ years old: gas stove heating versus cooking only

\begin{tabular}{lllll}
\hline & Crude OR & $\mathbf{9 5 \%} \mathrm{Cl}$ & Adjusted OR & $\mathbf{9 5 \%} \mathrm{Cl}$ \\
\hline Pneumonia $^{c}$ & 2.15 & $1.25,3.70$ & $2.08^{\mathrm{a}}$ & $1.08,4.03$ \\
Cough $^{c}$ & 1.45 & $0.99,2.12$ & $1.66^{\mathrm{b}}$ & $1.14,2.43$ \\
\hline
\end{tabular}

${ }^{a}$ Model adjusted for age, parental education, census region, race, household income $<\$ 20,000$, ever breastfed, and environmental tobacco smoke $(\mathrm{N}=3,240)$.

${ }^{b}$ Model adjusted for parental education, census region, race, household income $<\$ 20,000$, ever breastfed, and environmental tobacco smoke $(\mathrm{N}=3,084)$.

'The reference group for each comparison are homes that reported cooking only heating.

5 years of age had parental-reported pneumonia in the past 12 months was significantly greater (aOR: $1.76,95 \%$ CI: $1.04,2.98)$ among children who lived in a household where the participant reported that they did not use ventilation when operating their gas stove compared to children residing in homes that used ventilation when operating gas stoves. The association between parentalreported coughing was not significantly different between those who reported not using ventilation and those who did report using ventilation after adjusting for other risk factors (aOR: 1.23, 95\% CI: 0.87, 1.75).

The joint association of ventilation and heating are described in Figures 1 and 2. Compared to children residing in homes where the participants reported only using gas stoves for cooking and with ventilation, the odds of parental-reported pneumonia were three times higher (aOR: 3.06, 95\% CI: 1.32, 7.09) among children who lived in homes where the gas stoves were used for heat without ventilation after adjusting for confounders (Figure 1). The odds of a problem with parentalreported coughing was also significantly higher among this group of children who lived in homes where gas stoves were used for heat without ventilation $(\mathrm{aOR}$ : 2.07, 95\% CI: 1.29, 3.30) after adjusting for confounders (Figure 2). Compared to the reference group, the adjusted odds of parental-reported pneumonia and cough were not significantly different for children residing in a home where the participant reported using their gas stove for heat with ventilation or not using ventilation when using their gas stove for cooking only (Figures 1 and 2).

Table 3 Odds ratios for ALRI among children $<5$ years old: no gas stove ventilation versus ventilation

\begin{tabular}{lllll}
\hline & Crude OR & $\mathbf{9 5 \%} \mathrm{Cl}$ & Adjusted OR & $\mathbf{9 5 \%} \mathrm{Cl}$ \\
\hline Pneumonia $^{c}$ & 1.76 & $1.09,2.83$ & $1.76^{\mathrm{a}}$ & $1.04,2.98$ \\
Cough $^{c}$ & 1.04 & $0.77,1.40$ & $1.23^{\mathrm{b}}$ & $0.87,1.75$ \\
\hline
\end{tabular}

${ }^{\mathrm{a}}$ Model adjusted for age, parental education, census region, race, household income $<\$ 20,000$, environmental tobacco smoke, and ever breastfed $(\mathrm{N}=3,254)$.

${ }^{\mathrm{b}}$ Model adjusted for parental education, census region, race, household income $<\$ 20,000$, ever breastfed, and environmental tobacco smoke $(\mathrm{N}=3,099)$.

'The reference group for each comparison are homes that reported using ventilation.

\section{Discussion}

This study observed that the prevalence of pneumonia and problems with coughing in U.S. children less than 5 years of age were significantly associated behaviors related to operating gas stoves; namely using it for heat without ventilation. While each of these behaviors was associated with an increased likelihood of respiratory illness in this selected population, the odds of pneumonia and a problem with coughing was significantly higher only in children who resided in homes where gas stoves were used for heating without ventilation. This observation is important because ventilation and using a gas stove for heat are modifiable factors and provide an opportunity for public health intervention. For instance, approximately $90 \%$ of the respondents in this sample who did not use ventilation reported the absence of an exhaust vent near their stove. This suggests that significant infrastructure improvements regarding ventilation, beyond just behavior modification, are needed to improve health outcomes related to ventilation and gas stoves [55]. Moreover, and not surprisingly, we found that using a gas stove for heating or without ventilation occurred at greater frequency in lower socioeconomic status households as well as among African American households, even after adjusting for age of the home and census region (data not shown). The degree to which gas stove-related behaviors and housing conditions are a source of respiratory health disparities in the United States is unclear yet our findings suggest that it deserves further attention.

While this study is the first to examine the nationwide association between behaviors related to operating gas stoves and pneumonia prevalence in U.S. children, there is considerable evidence from epidemiological studies in developed countries that gas stoves used for cooking, heat or without ventilation are associated with an increased risk of chronic lower respiratory illnesses and symptoms in children [56-63]. Behaviors related to gas stove use has also been shown to be related to acute lower respiratory illness in young children. A crosssectional study $(\mathrm{n}=426)$ conducted in Hong Kong reported a dose-response relationship between the frequency of gas cooking, an indicator of gas stove-use intensity, and the prevalence of respiratory illnesses among children $\leq 6$ years who lived in a sector of the city with the lowest ambient air pollution [40]. Specifically, in homes where a gas stove was used for cooking $\geq 3$ meals per day the likelihood of pneumonia or bronchitis was 2.6 times higher $(\mathrm{OR}=2.6$; $95 \% \mathrm{CI}: 1.3,5.4)$ compared to children from homes where gas stoves were used for $\leq 1$ meal per day [40]. This study also found that children from homes with unvented gas stove were 3.7 times more likely to have pneumonia or bronchitis $(\mathrm{OR}=3.7 ; 95 \% \mathrm{CI}: 0.8,16.7)$ compared to children 


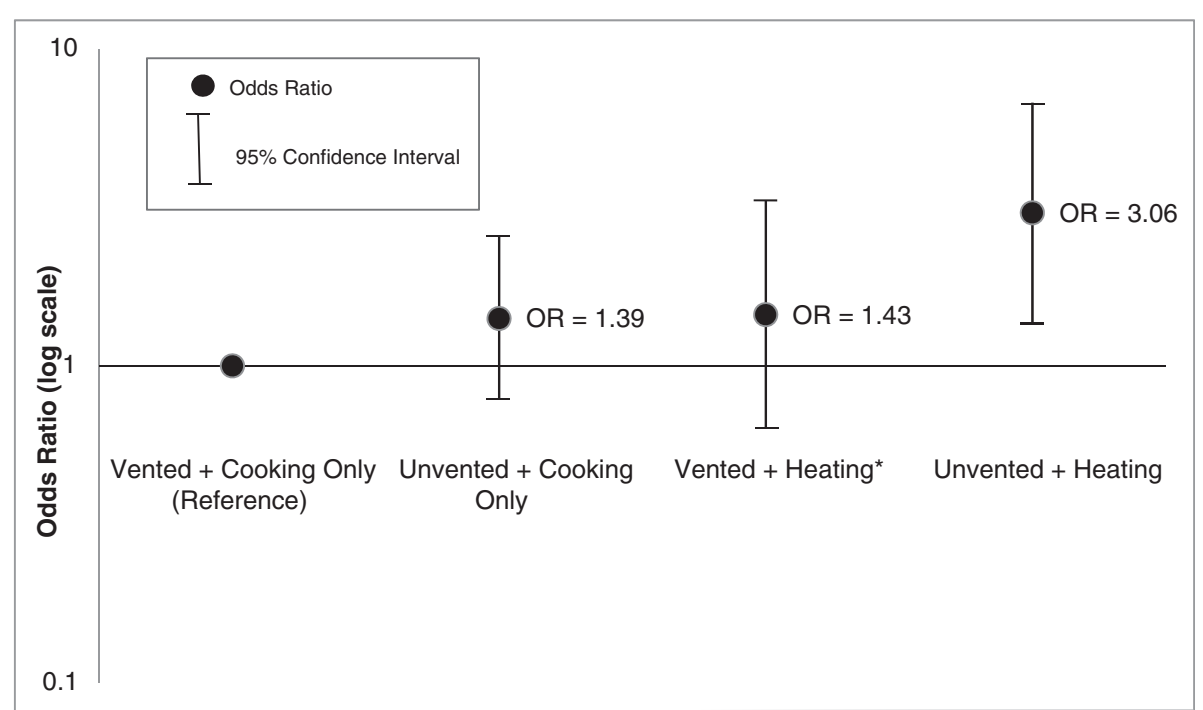

Figure 1 Odds ratios for Pneumonia among children $<5$ years old: comparison of heating and ventilation combined. *May be statistically unreliable, relative standard error (SE/percent) $>30 \%$.

from vented gas stove homes. MacIntyre et al. [64] examined the dose-response relationship between air pollutants which are also known to be emitted from gas stoves reported that the odds of pneumonia ORs increased by $30 \%$ and $76 \%$ with every ten ppb increase in $\mathrm{NO}_{2}$ and $\mathrm{PM}_{10}$. Another study that compared unvented gas heaters to vented gas heaters found an Odds Ratio of 1.16 (95\% CI: 1.01 - 1.34) for cough among school-aged children [29]. A recent home intervention study by Paulin et al. [65] found that adding an exhaust vent to a gas stove reduced indoor $\mathrm{NO}_{2}$ concentrations by $9.6 \mathrm{ppb}$ on average.
Interestingly, the magnitude of the effects observed in our study is comparable to the effect estimates described above $[29,40,64]$.

In light of recent research data that point to the importance of ventilation to reduce indoor air pollution such as nitrogen dioxide when operating a gas stove [47,65-67], it is important to consider the biologic plausibility that gas stove emissions could be related to ALRI. Firstly, data from epidemiologic research suggest that increasing nitrogen dioxide exposure is likely to increase risk of lower respiratory symptoms and ALRIs

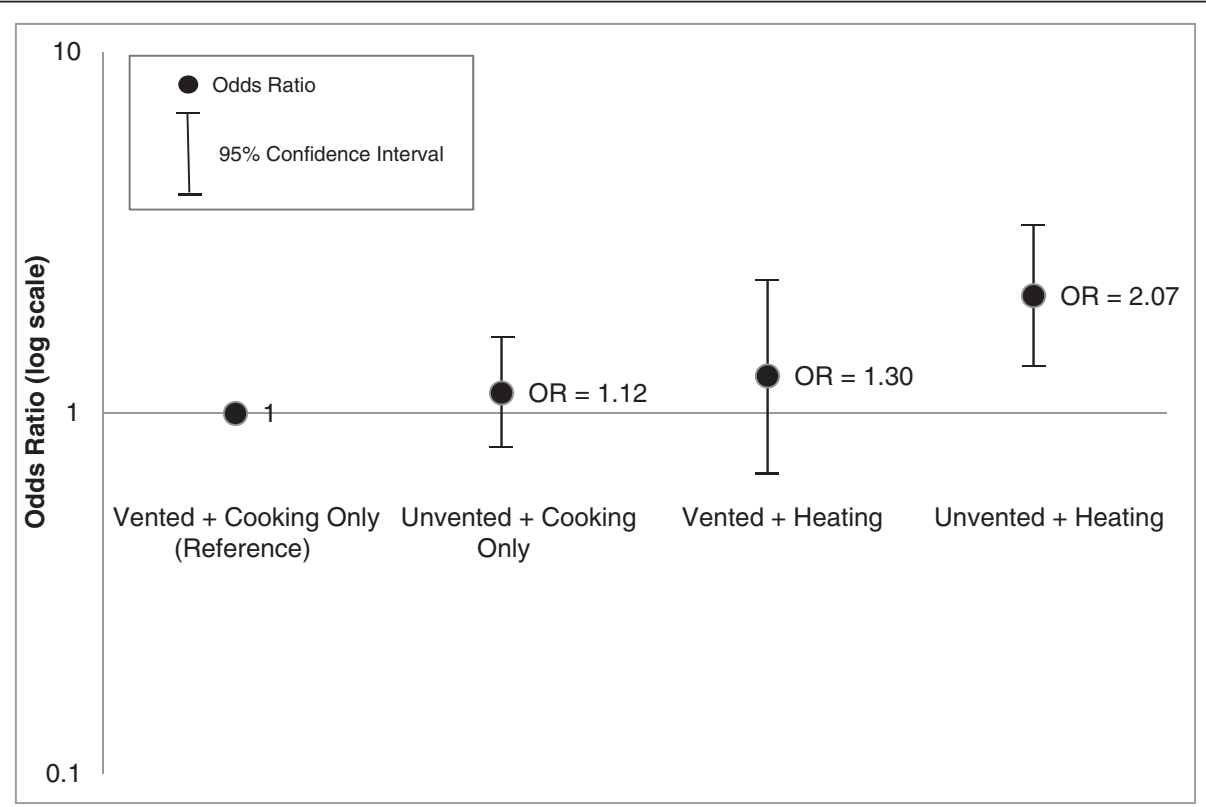

Figure 2 Odds ratios for Cough among children $<5$ years old: comparison of heating and ventilation combined. 
[29,31,44,64,68-75]. Experimental toxicological studies show that exposing bronchial epithelial cells to nitrogen dioxide causes oxidative stress [76], production of proinflammatory molecules $[77,78]$, suppression of the innate response $[79,80]$, impaired macrophage activation [81], and altered function of surfactant proteins which are critical in phagocytosis and inflammation processes [76]. Such effects may result in reduced host defenses against spread of viral or bacterial pathogens that cause ALRI [79-82]. An epidemiological study found that children of mothers who cook with a gas stove were significantly more likely $(\mathrm{OR}=17.1,95 \% \mathrm{CI}$ : $3.0-98.1)$ to spontaneously release TNF- $\alpha$ [83], an important indicator of an immune response to acute viral infections [84]. A separate study of children under 24 months found that the presence of a gas stove in the home was associated with a $46.5 \%$ increase $(\mathrm{p}<0.01)$ in T-helper 2 cytokines [85]. Moreover, an imbalance of T-helper 2/Thelper 1 cytokines has been associated with more severe cases of lower respiratory viral infections in young children [86] and in vivo experiments have shown that increased T-helper 2 cells were associated with increased susceptibility to pneumococcal pneumonia in a mouse model [87]. Taken together, these studies support a biological plausibility for our findings.

While our study has many strengths including the ability to adjust for multiple confounders in a large, nationally-representative sample of U.S. children, there are several limitations to this study that warrant consideration. Namely, these data are cross-sectional which prevents us from interpreting the temporality of the observed associations. Also, we relied upon parentalreported health outcomes in the past 12 months. Given this long recall period, recall bias is a potential limitation and may impact our findings. For example, if parents who reported not using ventilation or whose homes did not have an exhaust vent, were more likely to recall one of these respiratory illnesses in their child than parents who reported using ventilation our estimates may be biased away from the null and overestimate the association. Alternatively, if parents who did not report using ventilation or whose homes did not have an exhaust vent were less likely to recall one of these respiratory illness in their child, our estimate may be biased towards the null which would lead to an underestimate of the observed effects. If the recall bias between parents using or not using a gas stove for heating (or ventilation), there may be non-differential bias and our estimate may also be attenuated. It is also possible that parents who recalled that their children had pneumonia were also more likely to recall that their child had problems with coughing.

Another limitation is how we chose to group ventilation. Respondents were asked how often they used their ventilation (i.e. never, rarely, sometimes, always) when operating their gas stove. We opted to combine participants who rarely, sometimes and always used their exhaust vent into one category and compare them to those who never used their exhaust vent or did not have an exhaust vent near their gas stove. This binary approach likely includes some degree of misclassification given the ambiguity between the less frequent terms of use. However only 6 people reported never using their vent and 6 people reported rarely using their vent so the error contributed from this misclassification is likely to be small. It is also worth noting we adjusted for socioeconomic status using a categorical income variable that dichotomized participants as having a household income $>\$ 20,000$ and respondent education level. These covariates were chosen because they had the highest response rate and addressed two important factors related to poverty. Another limitation of our study was that we were unable to compare the effects of stove operating behaviors on respiratory illnesses in homes that used electric stoves since only respondents with a gas stove were asked about ventilation practices and using their stove for heat. Therefore, our study may only be generalizable to children residing in homes with a gas stove. In addition, there were no indoor air pollutants measured in NHANES which could be used to further characterize exposure. Also, these data are more than 25 year old and thus may not accurately reflect the current status of gas stove use behaviors. However, gas stoves remain commonplace in the U.S. [88] and more recent research suggests heating with a gas stove and poor ventilation is still prevalent in the US $[46,47,89]$. For instance, one study conducted in California found that among those who reported using a cooking appliance, as much as $61 \%$ did not use ventilation while cooking [89]. Also, we cannot discount the influence of unmeasured confounders that are likely to exist (i.e. climate).

\section{Conclusion}

In conclusion, we observed that U.S. children less than five years old who live in households with a gas stove which is used for heat without ventilation have the highest prevalence of pneumonia and cough. Additionally, using a gas stove for heat or without ventilation was also associated with higher prevalence of pneumonia and cough. These behaviors or housing conditions may be amenable to public health intervention due to their modifiable nature. More research is needed to establish the causality of these observations particularly as a driver of environmentally-determined health disparities. Also, since NHANESIII is now more than twenty years old and currently represents the only U.S. populationbased data set to examine the relationship between gas 
stove usage and respiratory illnesses, we recommend that future NHANES cycles incorporate such questions again so that health science researchers can evaluate whether circumstances have changed in the United States.

\section{Abbreviations}

ALRI: Acute lower respiratory infection; Cl: Confidence interval; NHANES III: Third National Health and Nutrition Examination Survey; OR: Odds ratio.

\section{Competing interests}

The authors declare that they have no competing interests.

\section{Authors' contributions}

ESC designed the study, conducted the statistical analysis and wrote the manuscript. ES assisted with the study design, reviewed the statistical analysis and interpretation of results, and participated in the drafting of the manuscript. AKH helped to conceptualize the study's research question, reviewed the interpretation of results and participated in the drafting of the manuscript. JM reviewed the interpretation of results and participated in the drafting of the manuscript. MLK assisted with the study design, reviewed the statistical analysis and interpretation of results, and participated in the drafting of the manuscript. All authors read and approved the final manuscript.

\section{Authors' information}

ESC is currently a PhD candidate in the College of Public Health and Human Sciences at OSU and holds an MS in Environmental and Occupational Health Exposures Science and an MS in Global Health Science.

ES is an epidemiologist and Associate Professor in the College of Public Health and Human Sciences and holds a PhD in Epidemiology from John Hopkins University.

AKH is a Professor and Co-director of the School of Biological and Population Health Sciences at OSU and holds a PhD in Public Health from OSU JM: Is an Associate Professor in Biostatistics within the College of Public Health and Human Sciences and holds a PhD in Statistics and MS in Mathematics.

MLK: Is an Assistant Professor in the College of Public Health and Human Sciences at OSU and holds a SCD in Environmental Health from the Harvard School of Public Health.

\section{Acknowledgements}

This work was supported by grants from the US National Institute of Environmental Health Sciences NIEHS Grant P42 ES016465 and P30 ES000210.

Received: 30 September 2014 Accepted: 15 January 2015 Published online: 04 February 2015

\section{References}

1. Rudan I, O'Brien KL, Nair H, Liu L, Theodoratou E, Qazi S, et al. Epidemiology and etiology of childhood pneumonia in 2010: estimates of incidence, severe morbidity, mortality, underlying risk factors and causative pathogens for 192 countries. J Glob Health. 2013;3:10401.

2. Centers for Disease Control and Prevention (CDC). VPD surveillance manual, 5th edition, pneumococcal disease: chapter 11-1. 12th edition. Atlanta, GA: Centers for Disease Control and Prevention; 2008.

3. Centers for Disease Control and Prevention (CDC). Pneumonia hospitalizations among young children before and after introduction of pneumococcal conjugate vaccine-United States, 1997-2006. MMWR Morb Mortal Wkly Rep. 2009;58:1-4

4. Talan DA, Moran GJ, Pinner RW. Progress toward eliminating Haemophilus influenzae type b disease among infants and children-United States, 1987-1997. Ann Emerg Med. 1999:34:109-11.

5. Gern JE, Rosenthal LA, Sorkness RL, Lemanske Jr RF. Effects of viral respiratory infections on lung development and childhood asthma. J Allergy Clin Immunol. 2005;115:668-74. quiz 675.

6. Jartti T, Gern JE. Rhinovirus-associated wheeze during infancy and asthma development. Curr Respir Med Rev. 2011;7:160-6.

7. Sly PD, Kusel M, Holt PG. Do early-life viral infections cause asthma? J Allergy Clin Immunol. 2010;125:1202-5.
8. Jackson S, Mathews KH, Pulanić D, Falconer R, Rudan I, Campbell H, et al. Risk factors for severe acute lower respiratory infections in children - a systematic review and meta-analysis. Croat Med J. 2013;54:110-21.

9. Dherani M, Pope D, Mascarenhas M, Smith KR, Weber M, Bruce N. Indoor air pollution from unprocessed solid fuel use and pneumonia risk in children aged under five years: a systematic review and meta-analysis. Bull World Health Organ. 2008;86:390-8C.

10. Ezzati M, Kammen DM. The health impacts of exposure to indoor ai pollution from solid fuels in developing countries: knowledge, gaps, and data needs. Environ Health Perspect. 2002;110:1057-68.

11. Smith KR, Mehta S. The burden of diseae from indoor air pollution in developing countries: comparison of estimates. Int J Hyg Env Health. 2003:206:279-89.

12. Baxter LK, Clougherty JE, Laden F, Levy JI. Predictors of concentrations of nitrogen dioxide, fine particulate matter, and particle constituents inside of lower socioeconomic status urban homes. J Expo Sci Environ Epidemiol. 2006;17:433-44.

13. Hansel NN, Breysse PN, McCormack MC, Matsui EC, Curtin-Brosnan J, Williams DL, et al. A longitudinal study of indoor nitrogen dioxide levels and respiratory symptoms in inner-city children with asthma. Environ Health Perspect. 2008;116:1428-32.

14. Loo CKJ, Foty RG, Wheeler AJ, Miller JD, Evans G, Stieb DM, et al. Do questions reflecting indoor Air pollutant exposure from a questionnaire predict direct measure of exposure in owner-occupied houses? Int J Environ Res Public Health. 2010;7:3270-97.

15. Semple S, Garden C, Coggins M, Galea KS, Whelan P, Cowie H, et al. Contribution of solid fuel, gas combustion, or tobacco smoke to indoor air pollutant concentrations in Irish and Scottish homes: Indoor air pollutant concentrations in Irish and Scottish homes. Indoor Air. 2012;22:212-23.

16. Wallace LA, Emmerich SJ, Howard-Reed C. Source strengths of ultrafine and fine particles due to cooking with a gas stove. Environ Sci Technol. 2004:38:2304-11.

17. Wallace L, Wang F, Howard-Reed C, Persily A. Contribution of gas and electric stoves to residential ultrafine particle concentrations between 2 and $64 \mathrm{~nm}$ : size distributions and emission and coagulation remission and coagulation rates. Environ Sci Technol. 2008:42:8641-7.

18. Belanger K, Triche EW. Indoor combustion and asthma. Immunol Allergy Clin North Am. 2008;28:507-19.

19. Casas L, Tischer C, Tiesler C, Brüske I, Koletzko S, Bauer C-P, et al. Association of gas cooking with children's respiratory health: results from GINIplus and LISAplus birth cohort studies: gas cooking and children's respiratory health. Indoor Air. 2012;22:476-82

20. Lin W, Brunekreef B, Gehring U. Meta-analysis of the effects of indoor nitrogen dioxide and gas cooking on asthma and wheeze in children. Int J Epidemiol. 2013:42:1724-37.

21. Moshammer H, Fletcher T, Heinrich J, Hoek G, Hruba F, Pattenden S, et al. Gas cooking is associated with small reductions in lung function in children. Eur Respir J. 2010;36:249-54.

22. Kile ML, Coker ES, Smit E, Sudakin D, Molitor J, Harding AK. A cross-sectional study of the association between ventilation of gas stoves and chronic respiratory illness in U.S. children enrolled in NHANESIII. Environ Health Glob Access Sci Source. 2014;13:71.

23. Lanphear BP, Aligne CA, Auinger P, Weitzman M, Byrd RS. Residential exposures associated with asthma in US children. Pediatrics. 2001;107:505-11.

24. Aldous MB, Holberg CJ, Wright AL, Martinez FD, Taussig LM. Evaporative cooling and other home factors and lower respiratory tract illness during the first year of life. Group Health Medical Assoc Am J Epidemiol. 1996;143:423-30

25. Belanger K, Gent JF, Triche EW, Bracken MB, Leaderer BP. Association of indoor nitrogen dioxide exposure with respiratory symptoms in children with asthma. Am J Respir Crit Care Med. 2006;173:297-303.

26. Burr ML, Anderson HR, Austin JB, Harkins LS, Kaur B, Strachan DP, et al. Respiratory symptoms and home environment in children: a national survey. Thorax. 1999;54:27-32.

27. Dockery DW, Speizer FE, Stram DO, Ware JH, Spengler JD, Ferris Jr BG Effects of inhalable particles on respiratory health of children. Am Rev Respir Dis. 1989:139:587-94.

28. Holscher B, Heinrich J, Jacob B, Ritz B, Wichmann HE. Gas cooking, respiratory health and white blood cell counts in children. Int J Hyg Environ Health. 2000;203:29-37. 
29. Marks GB, Ezz W, Aust N, Toelle BG, Xuan W, Belousova E, et al. Respiratory health effects of exposure to low-NOx unflued gas heaters in the classroom: a double-blind, cluster-randomized, crossover study. Environ Health Perspect. 2010;118:1476-82.

30. Sunyer J. Nitrogen dioxide is not associated with respiratory infection during the first year of life. Int J Epidemiol. 2004;33:116-20.

31. Volkmer RE, Ruffin RE, Wigg NR, Davies N. The prevalence of respiratory symptoms in South Australian preschool children. II. Factors associated with indoor air quality. J Paediatr Child Health. 1995;31:116-20.

32. Ware JH, Dockery DW, Spiro 3rd A, Speizer FE, Ferris Jr BG. Passive smoking, gas cooking, and respiratory health of children living in six cities. Am Rev Respir Dis. 1984;129:366-74.

33. Acevedo-Bolton V, Cheng K-C, Jiang R-T, Ott WR, Klepeis NE, Hildemann LM. Measurement of the proximity effect for indoor air pollutant sources in two homes. J Environ Monit. 2012;14:94.

34. Barnes BR, Mathee A, Shafritz LB, Krieger L, Zimicki S. A behavioral intervention to reduce child exposure to indoor air pollution: identifying possible target behaviors. Health Educ Behav Off Publ Soc Public Health Educ. 2004;31:306-17.

35. Cyrys J, Heinrich J, Richter K, Wölke G, Wichmann HE. Sources and concentrations of indoor nitrogen dioxide in Hamburg (west Germany) and Erfurt (east Germany). Sci Total Environ. 2000;250:51-62.

36. Diette GB, Hansel NN, Buckley TJ, Curtin-Brosnan J, Eggleston PA, Matsui EC, et al. Home indoor pollutant exposures among inner-city children with and without asthma. Environ Health Perspect. 2007;115:1665-9.

37. García Algar O, Pichini S, Basagaña X, Puig C, Vall O, Torrent M, et al. Concentrations and determinants of NO2 in homes of Ashford, UK and Barcelona and Menorca, Spain. Indoor Air. 2004;14:298-304.

38. Linaker $\mathrm{CH}$, Chauhan AJ, Inskip H, Frew A, Sillence A, Coggon D. Holgate: Distribution and determinants of personal exposure to nitrogen dioxide in school children. Occup Environ Med. 1996;53:200-3.

39. Linaker $\mathrm{CH}$. Personal exposures of children to nitrogen dioxide relative to concentrations in outdoor air. Occup Environ Med. 2000;57:472-6.

40. Wong TW, Yu TS, Liu HJ, Wong AHS. Household gas cooking: a risk factor for respiratory illnesses in preschool children. Arch Dis Child. 2004;89:631-6.

41. Zhang Q, Gangupomu RH, Ramirez D, Zhu Y. Measurement of ultrafine particles and other Air pollutants emitted by cooking activities. Int J Environ Res Public Health. 2010:7:1744-59.

42. Clougherty JE, Houseman EA, Levy JI. Source apportionment of indoor residential fine particulate matter using land use regression and constrained factor analysis: indoor-source apportionment using LUR and factor analysis. Indoor Air. 2011:21:53-66.

43. Dassen WG, Matsuki H, Kasuga H, Misawa K, Yokoyama H, Shimizu Y. Determinants of indoor NO2-concentration and the personal exposures of children and their mothers in Japanese homes. Tokai J Exp Clin Med. 1987;12:83-95.

44. Matsuki $H$, Kasuga $H$, Osaka F, Yanagisawa $Y$, Nishimura H. A comparative study on the health effects of smoking and indoor air pollution in summer and winter. Tokai J Exp Clin Med. 1985:10:427-37.

45. Rim D, Wallace L, Nabinger S, Persily A. Reduction of exposure to ultrafine particles by kitchen exhaust hoods: the effects of exhaust flow rates, particle size, and burner position. Sci Total Environ. 2012;432:350-6.

46. Zota A, Adamkiewicz G, Levy Jl, Spengler JD. Ventilation in public housing: implications for indoor nitrogen dioxide concentrations. Indoor Air. 2005:15:393-401.

47. Logue JM, Klepeis NE, Lobscheid AB, Singer BC. Pollutant exposures from natural gas cooking burners: a simulation-based assessment for southern California. Environ Health Perspect. 2013;122:43-50.

48. Centers for Disease Control and Prevention (CDC). Use of unvented residential heating appliances-United States, 1988-1994. MMWR Morb Mortal Wkly Rep. 1997;46:1221-4.

49. NHANES - NCHS Research Ethics Review Board Approval http://www.cdc gov/nchs/nhanes/irba98.htm

50. Chantry CJ. Full breastfeeding duration and associated decrease in respiratory tract infection in US children. Pediatrics. 2006;117:425-32.

51. Quraishi SA, Bittner EA, Christopher KB, Camargo CA. Vitamin D status and community-acquired pneumonia: results from the third national health and nutrition examination survey. PLoS One. 2013;8:e81120.

52. NCHS. NHANES III (1988-1994) Household Youth Data File Documentation. 1996; Catalog Number 77550: 1-266. http://www.cdc.gov/nchs/nhanes/ nh3data.htm\#1a
53. Neuman MI, Shah SS, Shapiro DJ, Hersh AL. Emergency department management of childhood pneumonia in the United States prior to publication of national guidelines. Acad Emerg Med. 2013;20:240-6.

54. Bate SL, Dollard SC, Cannon MJ. Cytomegalovirus seroprevalence in the United States: the national health and nutrition examination surveys, 1988-2004. Clin Infect Dis. 2010;50:1439-47.

55. Jin $Y, M a X$, Chen $X$, Cheng $Y$, Baris E, Ezzati M. Exposure to indoor air pollution from household energy use in rural China: the interactions of technology, behavior, and knowledge in health risk management. Soc Sci Med. 2006;62:3161-76.

56. Behrens T, Maziak W, Weiland SK, Rzehak P, Siebert E, Keil U. Symptoms of asthma and the home environment. The ISAAC I and III cross-sectional surveys in Münster, Germany. Int Arch Allergy Immunol. 2005;137:53-61.

57. Belanger K. Symptoms of wheeze and persistent cough in the first year of life: associations with indoor allergens, Air contaminants, and maternal history of asthma. Am J Epidemiol. 2003;158:195-202.

58. Berkey CS, Ware JH, Dockery DW, Ferris BG, Speizer FE. Indoor air pollution and pulmonary function growth in preadolescent children. Am J Epidemiol. 1986;123:250-60

59. Corbo GM, Forastiere F, Agabiti N, Dell'Orco V, Pistelli R, Aebischer ML, et al. Effect of gas cooking on lung function in adolescents: modifying role of sex and immunoglobulin E. Thorax. 2001;56:536-40.

60. De Bilderling G, Chauhan AJ, Jeffs JAR, Withers N, Johnston SL, Holgate ST, et al. Gas cooking and smoking habits and the risk of childhood and adolescent wheeze. Am J Epidemiol. 2005;162:513-22.

61. Garrett MH, Hooper MA, Hooper BM, Abramson MJ. Respiratory symptoms in children and indoor exposure to nitrogen dioxide and gas stoves. Am J Respir Crit Care Med. 1998;158:891-5.

62. Jarvis D, Chinn S, Luczynska C, Burney P. Association of respiratory symptoms and lung function in young adults with use of domestic gas appliances. Lancet. 1996;347:426-31.

63. Pershagen G, Rylander E, Norberg S, Eriksson M, Nordvall SL. Air pollution involving nitrogen dioxide exposure and wheezing bronchitis in children. Int J Epidemiol. 1995;24:1147-53.

64. Maclntyre EA, Gehring U, Mölter A, Fuertes E, Klümper C, Krämer U, et al. Air pollution and respiratory infections during early childhood: an analysis of 10 European birth cohorts within the ESCAPE project. Environ Health Perspect. 2014;1:107-13.

65. Paulin LM, Diette GB, Scott M, McCormack MC, Matsui EC, Curtin-Brosnan J, et al. Home interventions are effective at decreasing indoor nitrogen dioxide concentrations. Indoor Air. 2014;24:416-24.

66. Fabian MP, Stout NK, Adamkiewicz G, Geggel A, Ren C, Sandel M, et al. The effects of indoor environmental exposures on pediatric asthma: a discrete event simulation model. Environ Health Glob Access Sci Source. 2012;11:66.

67. Fabian MP, Adamkiewicz G, Stout NK, Sandel M, Levy Jl. A simulation model of building intervention impacts on indoor environmental quality, pediatric asthma, and costs. J Allergy Clin Immunol. 2014;133:77-84.

68. Aguilera I, Pedersen M, Garcia-Esteban R, Ballester F, Basterrechea M Esplugues A, et al. Early life exposure to outdoor air pollution and respiratory health, ear infections, and eczema in infants from the INMA study. Environ Health Perspect. 2012;3:387-92.

69. Fusco D, Forastiere F, Michelozzi P, Spadea T, Ostro B, Arcà M, et al. Air pollution and hospital admissions for respiratory conditions in Rome, Italy. Eur Respir J Off J Eur Soc Clin Respir Physiol. 2001;17:1143-50.

70. Neas LM, Dockery DW, Ware JH, Spengler JD, Speizer FE, Ferris Jr BG. Association of indoor nitrogen dioxide with respiratory symptoms and pulmonary function in children. Am J Epidemiol. 1991;134:204-19.

71. Ngo L, Mehta S, Do D, Thach T. The effects of short-term exposure on hospital admissions for acute lower respiratory infections in young children of Ho Chi Minh City, Viet Nam. Epidemiology. 2011;22:S228-9.

72. Speizer FE, Ferris Jr B, Bishop YM, Spengler J. Respiratory disease rates and pulmonary function in children associated with NO2 exposure. Am Rev Respir Dis. 1980;121:3-10.

73. Tramuto F, Cusimano R, Cerame G, Vultaggio M, Calamusa G, Maida CM, et al. Urban air pollution and emergency room admissions for respiratory symptoms: a case-crossover study in Palermo, Italy. Environ Health. 2011;10:31.

74. Wong TW, Lau TS, Yu TS, Neller A, Wong SL, Tam W, et al. Air pollution and hospital admissions for respiratory and cardiovascular diseases in Hong Kong. Occup Environ Med. 1999;56:679-83. 
75. Wong C-M, Thach TQ, Chau PYK, Chan EKP, Chung RY, Ou C-Q, et al. Part 4. Interaction between air pollution and respiratory viruses: time-series study of daily mortality and hospital admissions in Hong Kong. Res Rep Health Eff Inst. 2010;154:283-362.

76. Ciencewicki J, Jaspers I. Air pollution and respiratory viral infection. Inhal Toxicol. 2007;19:1135-46.

77. Devalia JL, Bayram H, Rusznak C, Calderón M, Sapsford RJ, Abdelaziz MA, et al. Mechanisms of pollution-induced airway disease: in vitro studies in the upper and lower airways. Allergy. 1997;52(38 Suppl):45-51. discussion 57-58.

78. Spannhake EW, Reddy SPM, Jacoby DB, Yu X-Y, Saatian B, Tian J. Synergism between rhinovirus infection and oxidant pollutant exposure enhances airway epithelial cell cytokine production. Environ Health Perspect. 2002;110:665-70

79. Becker S, Soukup JM. Effect of nitrogen dioxide on respiratory viral infection in airway epithelial cells. Environ Res. 1999;81:159-66.

80. Rose RM, Fuglestad JM, Skornik WA, Hammer SM, Wolfthal SF, Beck BD, et al. The pathophysiology of enhanced susceptibility to murine cytomegalovirus respiratory infection during short-term exposure to $5 \mathrm{ppm}$ nitrogen dioxide. Am Rev Respir Dis. 1988;137:912-7.

81. Becker S, Soukup JM. Exposure to urban air particulates alters the macrophage-mediated inflammatory response to respiratory viral infection. J Toxicol Environ Health A. 1999;57:445-57.

82. Jakab GJ. Modulation of pulmonary defense mechanisms against viral and bacterial infections by acute exposures to nitrogen dioxide. Res Rep Health Eff Inst. 1988;20:1-38.

83. Djuardi Y, Wibowo H, Supali T, Ariawan I, Bredius RGM, Yazdanbakhsh M, et al. Determinants of the relationship between cytokine production in pregnant women and their infants. PLoS One. 2009;4:e7711.

84. Neuzil KM, Tang YW, Graham BS. Protective Role of TNF-alpha in respiratory syncytial virus infection in vitro and in vivo. Am J Med Sci. 1996;311:201-4.

85. Duramad P, Harley K, Lipsett M, Bradman A, Eskenazi B, Holland NT, et al. Early environmental exposures and intracellular Th1/Th2 cytokine profiles in 24-month-old children living in an agricultural area. Environ Health Perspect. 2006;114:1916-22.

86. Hassan MA, Eldin AME, Ahmed MM. T - helper $2 / T$ - helper1 imbalance in respiratory syncytial virus bronchiolitis in relation to disease severity and outcome. Egypt J Immunol Egypt Assoc Immunol. 2008;15:153-60.

87. Kang C-I, Rouse MS, Patel R, Kita H, Juhn YJ. Allergic airway inflammation and susceptibility to pneumococcal pneumonia in a murine model with real-time in vivo evaluation. Clin Exp Immunol. 2009;156:552-61.

88. Nicole W. Cooking up indoor air pollution: emissions from natural gas stoves. Environ Health Perspect. 2014;122:A27-7.

89. Klug V, Lobscheid AB, Singer BC. Cooking appliance use in California homes — data collected from a Web-based survey. Berkeley, California: Lawrence Berkeley National Laboratory; 2011. p. 1-39.

\section{Submit your next manuscript to BioMed Central and take full advantage of:}

- Convenient online submission

- Thorough peer review

- No space constraints or color figure charges

- Immediate publication on acceptance

- Inclusion in PubMed, CAS, Scopus and Google Scholar

- Research which is freely available for redistribution 